\title{
Suicide, Jews and Judaism
}

\author{
Kate Miriam Loewenthal \\ Royal Holloway, University of London, \\ New York University in London, \\ Glyndwr University, Wales, \\ Heythrop College University of London
}

Keywords: suicide; Jewish law; suicide ideation; self-harm

\begin{abstract}
This article will examine the ambivalence in the views of Jewish authorities towards suicide. There are Jewish rulings which forbid the taking of one's own life, including requested euthanasia. There are seemingly contrary rulings which tolerate and sometimes admire suicide, particularly under conditions of religious persecution.
\end{abstract}

The article will attempt an overview of suicide rates in Jewish communities, indicating variations in different circumstances. The question of whether religiosity affects suicide will be raised and examined.

These variations - and of course other factors-may offer some clues to the precursors of suicide, and the processes which may be involved. The causal and risk factors in self-harm among Jews will also be examined.

The article then turns to post-suicide events, behaviours and attitudes in Jewish communities.

Introduction: Jewish law on suicide

The World Health Organisation (2017) estimates about 800000 completed suicides worldwide, accounting for $1.4 \%$ of all deaths. Suicide was the 17th leading cause of death in 2015, and the second leading cause of death among adolescents and young adults. There are about 20 attempted suicides for every completed suicide, with incomplete suicide a strong predictor of later completed suicide.

How do religious factors relate to suicide? This article will focus on the question in the Jewish community.

There are approximately 14 million Jews in the world, about 5 million in Israel, 6 million in the USA, with the remainder scattered in communities in Europe, South Africa, Australasia, the former Soviet Union, and South America, and in tiny groups or in isolation elsewhere.

Strictness of adherence to Jewish law varies. Jewish groups are often categorised by strictness of adherence expected or recommended by the synagogue which forms a centre of religious and social life: strictly orthodox, traditionally and modern orthodox, reform and other non-orthodox groups, non-observant and nonaffiliated. In Israel a common categorisation of religious grouping is strictly orthodox, traditional and secular. Within these very broad groups there are many sub-groups but it will not be helpful to describe them here. It is useful to bear in mind that while Jews may vary in adherence to and knowledge of Jewish religious law (Halacha) we cannot make firm predictions about adherence and knowledge from group identification. Nevertheless we can ask in this paper whether and how identification as a Jew, and as a Jew of particular degree of religiosity, might relate to suicide beliefs and behaviour.

There is striking ambivalence in Jewish law about suicide, and related attitudes and behaviours.g ambiguity. On the one hand the "duty of preserving life, including ones own, is considered paramount"; saving life is valued above all else (Jacobs 1995). Suicide is regarded as a grave sin, worse than murder. Life is owned by G$\mathrm{d}$, it is not seen as a human possession. The individual does not have the right to wound his/her own body, and certainly not to take his/her own life (Bailey and Stein 1995; Schwartz and Kaplan 1992). There are serious 
spiritual consequences to suicide in Judaism. When an individual commits suicide, the soul has nowhere to go (Kaplan and Schoenberg 1988; Gearing and Luzardi 2009). It cannot return to the body, nor can it enter any afterlife. It has lost opportunities to correct wrongdoings by actions in the physical world.

However in Jewish law suicide is not a punishable crime, and is legal in Israel. By contrast, following Shariah (Islamic law) which is also negative about suicide, suicide is illegal in many Muslim countries.

In Jewish religious law, the physician has permission to heal, but not to shorten or terminate life. In the case of a terminal illness, regular healing procedures must be maintained. Rabbinic advice must be sought in cases of uncertainty, for example whether it is obligatory to introduce "heroic measures" such as resuscitation or intubation if the illness is terminal (Loewenthal 2016).

On the other hand, in periods of religious persecution, suicide may be seen as meritorious: Kiddush HaShem: lit "Sanctification of the name (of G-d)": dying to prevent transgression (Shulchan Aruch Yoreh Deah, a). In times of religious persecution it is ruled to be meritorious to kill oneself or allowed oneself to be killed rather than transgress Jewish law. A Jew should also choose death rather than commit (in public) murder, idolatry or adultery.

The best-known example of this is an account by the historian Josephus of the mass suicide of nearly 1000 Jewish defenders of the fort of Masada by the Dead Sea, against Roman invasion (Schwartz and Kaplan 1992). The archaeological evidence for this is said to be controversial, but the heroism of the mass suicide continues to be held up as inspirational.

There are therefore two contrasting positions in Judaism regarding the moral and spiritual status of suicide.

\section{Suicide rates}

Jewish communities have been reported to have low suicide rates. Early reports included Dubin (1963), and Miller (1976). More recently, suicide rates in Israel were still reported lower than those of other countries, including America (Levav and Aisenberg 1989; Maris et al 2000; Gearing and Lizardi 2009). Kohn et al (1997) among others have concluded that suicide rates amongst both youth and adults in Israel are amongst the lowest in the world. For example in 2015 the suicide rate in Israel was 9.9 per 100,000, compared to 12.6 in the USA and 11.9 in Europe (WHO ). Suicide rates among young adult male Jewish Israelis climbed in the 1980s (Bursztein and Apter 2009), but rates broadly stabilised in 1990s, and with some fluctuation, overall Jewish suicide rates in Israel generally continued low compared to those in other countries. Comparative studies suggest that suicide rates are generally lower amongst Jews than the general population in predominantly Protestant communities (Danto and Danto 1983; Goss and Reed 1971; Levav et al. 1988; Williams 1997). Other countries with suicide rates lower than the Israeli rate include most Muslim countries. But, comparisons with Muslim countries and communities are more difficult. In many Muslim countries (e.g. Pakistan, UAE, Lebanon, Syria) suicide attempts are illegal, and punishable by imprisonment or other penalties. This might be the reason for the low suicide rate in these countries (WHO 2017). Also, there is likely to be under-reporting of suicide. In these countries the ratio of male to female suicides (2:1 or less) is generally much lower than in most other countries - including Israel, where the rate of nearly 4:1 male:female is comparable with that in most other countries (Lubin et al 2001; WHO 2017).

In Israel, the suicide rate among Muslims is lower than that among Jews, and this is not an effect of Israeli law, which allows suicide, but is likely to be an effect of a strong cultural-religious veto against committing and indeed acknowledging suicide. This effect may also exist in the Jewish community, but the veto may be less strong than among Muslims. There are some in the Jewish community who favour openness on the issue (Kremer 2015).

Bursztein and Apter (2009) remind us that suicide may not necessarily be defined similarly between countries, coroners and doctors. For example in Israel, death of a cancer patient who kills themselves will be recorded as caused by cancer, and many causes of death such as suffocation or falling from a height, are classified as undetermined causes. Some countries (e.g. Antigua, Nepal, Haiti) with very low or zero suicide rates on record 
may be inadequately resourced for keeping records of causes of death. Such factors must be born in mind when comparing suicide rates between countries.

Similarly demographers vary in definition of the term "Jew" - for example self-definition, definition by synagogue or other organisational membership, or surname. This is another factor which may be considered in estimates of Jewish suicide rates.

\section{Suicide and self-harm: precursors and risk factors}

A small amount of research has examined cultural-religious differences in beliefs about suicide (Ellis et al 1991., Kamal and Loewenthal 2002, Loewenthal et al 2003) The Reasons For Living Inventory (RFLI) (Linehan et al 1983) has generally been employed, together with some other measures such suicide ideation. The RFLI has been found to predict lesser suicidal ideation and fewer reported suicide attempts (Bakhiyi et al 2017; Laglaoui et al 2017).

Only one of these studies on suicide beliefs included Jews (Loewenthal et al 2003). This limited evidence suggests that Jewish beliefs about suicide may reflect the generally low suicide rates reported among Jews: high scores on the Reasons for Living Inventory (RFLI), especially on moral and religious objections to suicide; Jews also thought suicide less acceptable under certain circumstances, for example incurable disease, than did those of Protestant background.

What is known about the sociodemographic correlates and precursors of suicide among Jews? In Israel, overall suiciderates have fluctuated but are relatively low. However rates higher among Jews than among Arabs especially Muslim Arabs: here rates may appear to be low due to under-reporting. Israel is the only country in the Middle East that reports suicide figures to the WHO, so comparisons between rates for Jews in Israel and Arabs outside Israel cannot be made reliably.

Among Jews in Israel, the high risk groups (Bursztein and Apter 2009) are

- young men in the army. Israel exercises compulsory conscription for both men and women, though Arabs are not liable for conscription. Israel is a relatively tiny country with a population of about 8 million , surrounded by hostile countries - Israel's immediate neighbours are Egypt, Jordan, Lebanon and Syria, all hostile Arab countries, with populations totalling about 129 million (http://worldpopulationreview.com/countries 2017). They are normatively set on the destruction of Israel, and military attacks on Israel are frequent. Young Israeli men face a high likelihood of severe combat stress. Other countries in the west often do not practice conscription and may not be so often in a state of conflict. Comparisons with young men from countries with lower exposure to combat could be of interest.

- Immigrant groups in Israel, particularly Ethiopians and those from the former Soviet Union. Immigration is known to be a source of significant stress: economic hardship, family separation, cultural adaptation, loss of status in the community and/or in professional practice. Suicide risk may be affected by the cultural background of the two high-risk immigrant groups, in whose countries of origin Jewish norms are not generally religious, and reasons for living may not be as compelling as in mainstream Jewish or orthodox communities elsewhere.

- the elderly: recognised stress factors among the elderly include loss of social support, loss of occupation, loss of status, failing health and poor mobility. A particular factor in Israel can be the resurgence and rise in post-traumatic stress symptoms in holocaust survivors following retirement.

- depression may not be risk factor for suicide and self-harm thoughts and behaviours for Jews (Wilchek-Aviad and Malka 2016): in other groups of people suicide risk is greater among those suffering from mental illnesses, with depression carrying the highest risks of suicide.

This section should include at least a brief allusion to the effects of anti-semitism, for example and notoriously during the holocaust period (1933-1945): there have unfortunately been many other times and places in which 
severe Jewish persecution has occurred. Larson (2011) evokes the early years of the holocaust period in Germany. With the massive increase in Jewish suicide as anti-semitic persecution increased in virulence and intensity many individuals lost all hope of anything to cling to. Larson cites a report that in 1932-4 the suicide rate in Berlin was a massive 70.2 per 100,000. This likely became much higher as persecution and deportation increased, but conditions became impossible for keeping records. Some Jews determined not to kill themselves: Frankl (1986) suggested the importance of feeling purpose in life, enabling some individuals to refrain from suicide when deported to concentration camps.

Religiosity may be a protective factor against suicide and some work suggest that this may be the case among Jews. A recent study in Israel compared the strictly (ultra-orthodox) and orthodox with non-practicing Israelis and found that suicide and self-harm thoughts and behaviours in the non-practising groups to be twice the rate in the religious groups (Amit et al 2014). Another study (Wilchek-Aviad and Malka 2016) however found that although the religious were less depressed than the secular, there were no differences in suicide rates between the two groups. A media report (Kremer 2015) suggested high rates of suicide among those leaving the more religious sectors of Jewish society, particularly perhaps when substance is involved both as a causal factor in defection, and an effect.

Therefore the effects of religiosity is unclear and further research would be useful.

\section{Post-suicide}

According to strict Jewish ruling, individuals who commit suicide may not receive traditional post-death rituals such as a proper burial (Kaplan and Schoenberg 1988), although in current times this is not strictly applied. The current rabbinic view allows burial in a regular Jewish cemetery, on the grounds that a person would only kill themselves when the mind is disturbed, and therefore could not have committed suicide deliberately. Therefore in the current period and in the cultures in which Jews live, suicide is the result of a disturbed mind therefore not regarded as halachically culpable.

As mentioned, in the past a person who committed suicide was said to be buried in a separate part of the cemetery; relatives did not sit shiva (Shulchan Aruch Yoreh Deah). Shiva is a 7-day period in which close relatives wear torn clothes, sit on low seats, and receive consolatory visits. In current times, shiva is normally observed by relatives following a suicide.

It is worth noting that in modern Israel, suicide is legal - euthanasia and physician assisted death are not; however suicide in the context of terminal illness such as cancer is recorded as death due to the illness. Cases of possible suicide may be described in the community as death due to illness, not suicide; this may spare relatives' additional pain.

Suicide does cast many extra burdens on family and friends, in addition to the burdens already born by the bereaved. Grief and mourning are complicated by feelings such as horror in envisaging the suicidal state of mind, anger at the circumstances that provoked this disturbance, frustration and perhaps self-blame that the desperation was not shared and that something might have done to prevent the suicide. These burdens are not unique to Judaism. What may be unique is the shiva, which is often suggested to be helpful for the mourning process, but which may be complicated by the shadow cast by knowledge of the stigma placed (by Jewish law and custom) on suicide in the past, and which may still remain.

\section{Jewish prevention services}

A study reported in 2004 (Loewenthal \& Brooke-Rogers) examined the psychological support services provided by some of many culturally and religiously-appropriate Jewish support groups and helplines. These directly or indirectly address suicide. The Jewish community is well provided with such services. Many of the members of the Jewish public who were interviewed had not heard of or were poorly informed about many of these 
services, but where they had been used, reports were generally positive and their cultural and religious sensitivity was appreciated. There were said to be several ways in which the services could be improved: organisations need to be vigilant over confidentiality, to improve the dissemination of information, particularly among statutory sector professionals who deal with the community, and improve the reliability of funding. Work is needed demonstrating that the Jewish support groups and helplines are meeting demonstrable needs effectively.

A recent press report on the UK Jewish helpline Miyad (Galbinski 2014) said that about 2,000 calls a year are received. There are about 60 trained volunteers. Miyad's work corresponds to the work of Samaritans, but it is culture-specific. Angela Kamiel, Jewish Helpline's vice-chairman said "We're a Jewish helpline, so there's a context their story fits into that we understand. We understand the issues people are dealing with; there's a lot that doesn't need to be explained... Indeed, the charity takes its Jewish principles a step further. "We're not a religious organisation, but we are bound by halachic principles and we try to preserve life...We would try to get a suicidal person through until tomorrow, to stay with us step by step."

Psychotherapy in its early years was predominantly practiced by Jews. There was however some hostility from some strictly orthodox: for example Freud and his cohorts were described as charlatans by one orthodox rabbi (see Loewenthal, 2007). Nevertheless in recent years Jewish communities of all degrees of religiosity have developed counselling and support services that are seen to be culturally and religiously appropriate. Nowadays it is possible to find a Jewish psychotherapist - even a strictly religious Jewish therapist if wished: clients fear that otherwise their religious behaviour and feelings may be misunderstood and misinterpreted as sign of mental illness, and it has been reported that Jewish clients feel better understood by a Jewish therapist. However they prefer anonymity and prefer to choose a therapist from outside their own social circle (Loewenthal and Brooke-Rogers 2004)

Many - indeed most or all - forms of psychotherapy may reduce the risk of suicide, though suicide measures are not always included in studies of effectiveness. Most of the original practitioners of psychotherapy were Jewish: when young I remember being told by my head of department that a psychotherapist is a Jewish doctor who can't stand the sight of blood.

Recent examples which have demonstrated the effectiveness of psychotherapy in suicide prevention include the following studies of people at very high risk of suicide: deliberate self-harmers, and people with medication-resistant psychosis - these studies did not explicitly involve Jews but are cited as examples of some of the forms of therapy likely to be adopted by Jewish support services:

Erlangsen et al (2015) in a large Danish study examined people who had deliberately self-harmed. They followed them up over 20 years. 5,768 recipients of psychosocial therapy were compared with 17,034 people who did not receive therapy. There was a lower risk of repeated deliberate self-harm and general mortality in recipients of psychosocial therapy after short-term and long-term follow-up, and a protective effect for suicide after long-term follow-up.

Avatar therapy is specifically for those with medication-resistant psychosis (Leff et al, 2013). Using specific software, patients with medication-resistant Sz designed faces to match the voices they hear. With therapeutic support, patients converse with the voice(s) and convert them to become supportive. In some cases the voices disappear altogether. Apart from the effects on voices, this therapy improves mood, and diminishes suicide risk.

\section{Conclusion}

Jewish law and custom and social attitudes generally converge on maintaining the tradition of placing a massive positive value on human life and its sanctity. There is a little empirical work to support the impact of these values on actual beliefs held by Jews. Although there is a tradition which may allow suicide under specific circumstances, particularly when religious observance is threatened, the weight of Jewish tradition does not condone suicide. This may account for systematic effect observed since records began to be kept, that Jewish suicide rates are low compared to other religions and cultures. There is very limited work on the question whether, within the Jewish community, suicide rates are lower among the more religious. As well as religiosity, other possible risk factors are reviewed. 
The Jewish community offers a range of support services for those at risk of suicide, and the Jewish community has also been a source of therapies and other services available outside the community.

\section{References}

Amit, B.H., A. Krivoy, I. Mansbach-Kleinfeld, G. Zalsman, A.M. Ponizovsky, M. Hoshen, I.Farbstein, A.Apter, A. Weizman, and G. Shoval. 2014. Religiosity is a protective factor against self-injurious thoughts and behaviors in Jewish adolescents: Findings from a nationally representative survey. European Psychiatry 29:509-513

Bailey, W.T., and L.B. Stein. 1995. Jewish affiliation in relation to suicide rates. Psychological Reports 76: 561-562.

Bursztein, C., and A. Apter. 2009 The epidemiology of suicidal behaviour in the Israeli population. pp 267-285. In Levav, I. (Editor) Psychiatic and Behavioral Disorders in Israel. Jerusalem: Israel Ministry of Health.

Cohn, H.H. 1972. Suicide. Encyclopedia Judaica. Jerusalem: Encylopedia Judaica.

Dubin L.I. 1963 Suicide in Jewish History. In Suicide: A Sociological and Statistical Study. New York: The Ronald Press.

Erlangsen, A., B.Damlind, P.Qin, E. Stenager, K.J.Larsen, A.G. Wang, M.Hvid, A.C.Nielsen, C.M. Pedersen, J.Winsløv, et al. 2015 Short-term and long-term effects of psychosocial therapy for people after deliberate self-harm: A register-based, nationwide multicentre study using propensity score matching. The Lancet, Psychiatry 2: 49-58. https://doi.org/10.1016/S2215-0366(14)00083-2

Frankl, V.E. 1986 The Doctor and the Soul. New York: Basic Books.

Galbinski, A. 2014. Jewish helpline is a lifeline for those with nowhere to turn. Jewish News, July 10, 2014, accessed November 19, 2017.

Gearing, R.E., and D.Lizardi. 2009. Religion and suicide. Journal of Religion and Health 48: 332-341. doi:10.1007/s10943-008-9181-2.

Gross M.E.W., and J.I. Reed. Suicide and eligion: A study of white adults in New York City, 1963-67. Life Threatening Behaviour 1971: 163-177.

Jacobs, L. 1995 The Jewish Religion: A Companion. Oxford: Oxford University Press.

Josephus, F. 1985 edition.+ The Jewish War. Harmondsworth, Middlesex: Penguin.

Kamal, Z., and K.M.Loewenthal. 2002. Suicide beliefs and behaviour among young Muslims and Hindus in the UK. Mental Health, Religion and Culture 5: 111-118.

Kaplan, S.J. and L.A. Schoenberg. 1988. Defining suicide: Importance and implications for Judaism. Journal of Religion and Health 27: 154-156.

Kohn, R., I. Levav, B. Chang, B. Halperin, and P. Zadka, P. 1997. Epidemiology of youth suicide in Israel. Journal of the American Academy of Child and Adolescent Psychiatry 79: 468-473.

Kremer, W. 2015. Breaking the silence on Jewish suicide. BBC News, BBC World Service, 6 August 2015. Accessed 2 December 2017.

Larson, E. 2011. In the Garden of Beasts. pp. 191-2, 223-4. New York: Broadway Paperbacks. 
Levav, I. and Aisenberg, E. 1989. Suicide in Israel: Cross national comparisons. Acta Psychiatrica Scandinavica 79: 468-473.

Linehan, M.M., J.L.Goodstein, S.L.Nielsen, and J.A. Chiles J. A. 1983. Reasons for staying alive when you are thinking of killing yourself: The Reasons For Living Inventory. Journal of Consulting and Clinical Psychology 52: 276-286.

Loewenthal, K.M. and M. Brooke-Rogers. 2004. Culture sensitive support groups: How are they perceived and how do they work? International Journal of Social Psychiatry 50: 227-240.

Loewenthal, K.M., A.K.MacLeod, S. Cook, M.J.Lee, and V.Goldblatt, V. (2003) The suicide beliefs of Jews and Protestants in the UK: How do they differ? Israel Journal of Psychiatry 40: 174-181.

Loewenthal, M.M. Physician assisted death. Paper given at Toronto University Medical School, 12 April 2016.

Lubin, G., S. Glasse, V. Boyko, and V. Barrell. 2001. Epidemiology of suicide in Israel: A nationwide population study. Social Psychiatry and Psychiatric Epidemiology 36: 123-127.

Israel Ministry of Health. 2000. Suicides ages 15 and over by age and sex. In Mental Health Annual Statistics. www.health.gov.il. Accessed 2 December 2017.

Maris, R. W., A.L. Berman, and M.M. Silverman. 2000. Comprehensive Textbook of Suicidology. New York: Guilford Press.

Miller, L. 1976. Some data on suicide and attempted suicide of the Jewish population in Israel. Mental Health and Society 3: 178-181.

Schwartz, M., and K.J. Kaplan. 1992. Judaism, Masada, and suicide: A critical analysis. Journal of Death and Dying 25: 127-132.

Shulchan Aruch Yoreh Deah.a. 2017. A Comprehensive Review on the Everyday Halachos of Yoreh Deah, 157 (Chazarah Berurah Hilchos Hayom Yomyim). Create Space Independent Publishing Platform.

Shulchan Aruch Yoreh Deah.b. 2017. A Comprehensive Review on the Everyday Halachos of Yoreh Deah, 345 (Chazarah Berurah Hilchos Hayom Yomyim). Create Space Independent Publishing Platform.

WHO (World Health Organisation). 2015. List of countries by suicide rate. https://en.wikipedia.org/wiki/List_of_countries_by_suicide_rate. Accessed 15 Nov 2017.

Wilchek-Aviad, Y. and M. Malka. 2016. Religiosity, Meaning in Life and Suicidal Tendency Among Jews. Journal of Religion and Health 55: 480-494.

World Population Review. 2017. http://worldpopulationreview.com/countries

Accessed 29 November 2017 